\title{
Expert stakeholders' perception of nanotechnology: risk, benefit, knowledge, and regulation
}

\author{
Simon Larsson (D) - Magnus Jansson • Åsa Boholm
}

Received: 27 October 2018 / Accepted: 28 February 2019 / Published online: 15 March 2019

(C) The Author(s) 2019

\begin{abstract}
This study is positioned in a multidisciplinary research field addressing questions of innovation, foresight, risk perception, regulation, and the role of stakeholder experts as regards nanomaterials and nanotechnology. Nanotechnology is an innovative scientific field with many potential societal benefits but also high uncertainty about risks to human health and the environment. This study is based on a survey distributed to a sample of 237 expert stakeholders in Sweden working in the field of nanotechnology innovation and regulation. The sample comprises experts in both industry and government organizations. The paper explores the expert's assessment of benefits, risks, and their views of nanotechnology regulation. The experts generally agreed on the need for further regulation of nanotechnology, although they differed in their support for different regulatory measures. Support for government regulation was increased by greater perceived risk and by ethical concerns, while perceived benefit decreased support for government regulation. If nanotechnology was important for the respondent's organization of affiliation, support for government regulation decreased. Experts in government organizations were more in favor of stronger government regulation, perceived higher risks, and were more concerned about the ethical implications of nanotechnology than were the industry
\end{abstract}

S. Larsson $(\bowtie) \cdot$ M. Jansson

Gothenburg Research Institute, Gothenburg School of Business, Economics and Law, University of Gothenburg, Postal Address: Box 603, 40530 Göteborg, Visiting Address: Viktoriagatan 13

Plan 3, 41125 Göteborg, Sweden experts. While previous research has discussed views of experts, as well as comparing the attitudes of the general public with experts, this study contributes to the field by analyzing and identifying differences between industry experts and experts working in government.

Keywords Nanotechnology $\cdot$ Experts $\cdot$ Stakeholders · Risk perception $\cdot$ Risk psychology $\cdot$ Regulations

\section{Introduction}

Nanotechnology has been described as one of the most important scientific frontiers and as the defining science of the twenty-first century (Anderson 2007). Commonly defined as the study or manipulation of matter in the 1$100 \mathrm{~nm}$ size range, it encompasses various techniques to change the properties of particles at the molecular level to obtain new qualities with a broad range of applications. Having qualities such as strength, durability, water resistance, ability to absorb UV light, and increased conductivity, engineered nanomaterials are used in areas as diverse as electronics, coatings, cosmetics, textiles, and medicine. Nanotechnology is associated with promises of radically improved consumer products, revolutionary

\footnotetext{
Å. Boholm

School of Global Studies, University of Gothenburg, Postal Address: Box 700, 40530 Göteborg, Visiting Address:

Konstepidemins Väg 2, 41314 Göteborg, Sweden
} 
innovation in life science, and new environmental technology and is predicted to contribute to more resourceefficient production, improved healthcare, new jobs, and economic growth.

Large amounts are being spent globally on nanotechnology research in both the private and public sectors. In 2011, an estimated SEK 1.2 billion was spent by private and public nanotechnology research funders in Sweden (Hartmanis 2013). In 2010, 694 researchers were working on nanotechnology in various disciplines at all major Swedish universities. Sweden has good research infrastructure with advanced laboratories for nanotechnology research (Hartmanis 2013), and the Swedish public is generally positive toward nanotechnology innovation and products (Larsson and Boholm 2018). Nanotechnology is expected to have high potential to generate economic growth and new jobs in Sweden (Hartmanis 2013).

Nanotechnology has great promise, but there are still concerns about the safety of engineered nanomaterials and nanotechnology applications, leading to several risk management and regulatory challenges. The toxicity of manufactured nanoparticles is not entirely predictable from the toxicity of the source materials in bulk or molecular form, and assessing the toxicity of nanomaterials is demanding due to systemic and structural complexities and physical-chemical-biological interactions at the nano level for any specific nanomaterial (Miller and Wickson 2015; Renn and Roco 2006). Although there is a growing body of research into the toxicity of various engineered nanoparticles, uncertainty remains about future use, exposures, and long-term effects regarding ecosystems and human health (Fadeel et al. 2017). That methods for describing, characterizing, and testing nanomaterials are still partly lacking adds to the uncertainty about the potential harmful effects of nanomaterials (OECD 2012, 2013).

There is no straightforward way to introduce nanospecific safety prescriptions and regulations, and there is ongoing political and scholarly debate on how nanotechnology should best be regulated. One reason for these difficulties is that nanotechnology, nanoparticles, and nanomaterials refer to diverse materials and techniques used in many different components and products (Pidgeon et al. 2009). There is a lack of consensus on definitions of nanomaterial and nanoparticle (Boholm and Arvidsson 2016), and rigorous risk assessments and great uncertainty make it difficult for scientists to produce policy-relevant information in the field (Ho et al. 2011). Furthermore, it is politically challenging to legislate and implement regulation covering global production chains. The regulation of nanotechnology arguably poorly fits existing traditional regulatory frameworks (Bosso 2016). New ways of developing regulation better suited to handling complex international product chains have been called for (Beaudrie et al. 2013; Grieger et al. 2010; Wang et al. 2013).

The manufacturing and use of engineered nanomaterials in Sweden is currently covered by a patchwork of laws and regulations. In the last decade, there have been several calls to introduce nano-specific regulations in Europe and the USA, given the specificities of engineered nanoparticles and nanomaterials. In Europe, there are currently some nano-specific regulations, including the mandatory labeling of nanoproducts in cosmetics and sunscreens. In most cases, however, nanotechnology research, manufacturing, imports, and sales are regulated by laws and regulations not specifically targeting nanotechnology and nanomaterials (Hansen and Baun 2012). However, EU Member States recently voted in favor of the EU Commission's suggestion to introduce nanospecific regulations within REACH (Registration, Evaluation, Authorisation and Restriction of Chemicals) calling for information about nanomaterial ecotoxicity and the capacity of specific nanomaterials to be absorbed into the human body. These new regulations will be applied starting in January 2020 (Buxton 2018).

Various stakeholder organizations in Swedish society, including government organizations, industry, unions, and civil society organizations, are concerned with nanotechnology innovation and regulation. Experts within these organizations work in the areas of, for example, innovation, regulation, risk assessment, and work environment (Larsson et al. 2017). These experts have important roles in society because they can be expected to be working at the forefront of the safe development and use of nanotechnology applications. While some organizations work primarily on producing and promoting nanotechnology, others are primarily concerned with ensuring that the materials used are safe for humans and the environment. The various stakeholders are jointly concerned about the safe development of useful products and applications, but, depending on the organization, they have different emphases and might have different understandings of nanotechnology-related issues. Stakeholders are known to have different rationales for decision-making and problem assessment depending on 
their organizational role, responsibility, and culture (Apostolakis and Pickett 1998; Jenkins-Smith and Bassett 1994). Different actors can therefore be expected to have divergent views of nanotechnology regulation and different understandings of nanotechnology risk and benefit. Given the great uncertainty in the nanotechnology field and the resource-demanding nature of risk assessment, scholarly debate has argued that stakeholder deliberation is central to the successful development and safe use of nanotechnology (Hansen 2010; Renn and Roco 2006; Shatkin et al. 2010).

This is a study of expert stakeholders working with issues related to nanotechnology in Swedish society. The overarching aim of this study is to investigate the views of expert stakeholders in Sweden who work in industry or government organizations as to the benefits, risks, and regulation of nanotechnology. This research addresses the influence of perceived risk/benefit on nanotechnology regulation; differences in perception of nanotechnology depending on organizational affiliation; influence of self-rated knowledge on attitudes toward nanotechnology; and influence of ethical considerations, gender, and education level on attitudes toward nanotechnology, factors known from previous research to influence attitudes toward nanotechnology risk and benefit.

While previous research has discussed views of experts, as well as comparing the attitudes of the general public with experts, this study contributes to the field by analyzing and identifying differences between industry experts and experts working in government. The study improves our knowledge of expert stakeholders and their views and of their agreement or disagreement on problem definitions and solutions concerning nanotechnology innovation. Because expert stakeholders have a key role as translators between science and industry, between science and policy, and, not least, between policy and industry, they are crucial to the successful and effective societal management of nanomaterials.

The paper proceeds as follows. First, we review previous studies of risk perception and attitudes toward nanomaterial regulation and present the hypotheses to be tested in the study. Second, we present the methodology of the study. In the third section, we present the results of the study. In the fourth section, we discuss the results and their implications as well as discussing limitations of the study and, finally, in the conclusion, we summarize the results.
Previous research: perception of the risks, benefits, and regulation of nanotechnology

In 2008, Besley et al. wrote that there were many studies of how the general public perceives nanotechnology, but few investigating comparable attitudes of scientists and other experts. A decade later, this situation has changed. Now, many publications examine expert views of nanotechnology, as well as how scientists and experts from different disciplines and with different societal roles evaluate risks and benefits, and what influences their attitudes. Experts' views of nanotechnology have been considered worth studying because experts have a privileged knowledge position, influencing regulations, political decisions, and implementation, as well as helping shape public opinion by participating in public debate (Gupta et al. 2013; van Dijk et al. 2017). Prevalent themes in these studies are how experts evaluate the risks and benefits of nanotechnology and their views of regulation. The studies demonstrate that experts' perceptions of nanotechnology vary with both internal factors (e.g., whether risk perception influences the perceived benefit of nanotechnology and attitudes toward regulation) and external factors (e.g., gender, religion, political views, and media habits).

Before discussing the results of these previous studies of experts, we will briefly review studies of the general public's views of nanotechnology. Public attitudes toward nanotechnology have been considered to merit study because public acceptance is such an important factor for the successful commercialization of new technologies. Given the backlash against GM technology and the controversies surrounding nuclear power, there is arguably an acute need to consider public opinion when making policy decisions affecting new technologies (Priest 2011). Given the poor general knowledge of nanotechnology, it has also been argued that studies of lay understandings of nanotechnology and of what influences lay decisions would yield insight into how laypeople assess new technology in general. Studies of public attitudes toward nanotechnology have focused on the public's knowledge, views of risks and benefits, and views of nanotechnology regulation (Besley 2010; Corley et al. 2011; Gaskell et al. 2005; Kim et al. 2014; Larsson and Boholm 2018; Macnaghten 2010; Scheufele and Lewenstein 2005; Pidgeon et al. 2009; Priest et al. 2011; Siegrist et al. 2007; Su et al. 2015). 
A common finding is that the public have poor knowledge of nanotechnology but are mainly positive toward nanotechnology innovation and perceive little associated risk (Besley 2010; Gaskell et al. 2005; Larsson and Boholm 2018; Pidgeon et al. 2009; Priest et al. 2011). Another important finding is that there is great variability in the acceptability of nanotechnology depending on its intended use (Cacciatore et al. 2011; Larsson and Boholm 2018; Siegrist et al. 2007). High perceived risk associated with nanotechnology among respondents correlates with less support for nanotechnology applications (Scheufele and Lewenstein 2005). A finding of this literature is that lay views are influenced by value predisposition as indicated by, for example, religion, political views, and other heuristics (i.e., mental shortcuts or associations). In the USA, levels of religiosity are found to affect lay attitudes, respondents with higher religiosity being more inclined to see risk and be less supportive of nanotechnology (Brossard et al. 2009; Ho et al. 2010, 2011; Scheufele et al. 2009).

Another factor proven to be associated with a positive view of nanotechnology is trust in or deference to scientific authority (Lee et al. 2005). A study of the general public in the USA ( $\mathrm{Su}$ et al. 2015) concluded that value predispositions also played a critical role in influencing attitudes toward nanotechnology regulation, with respondents reporting high religiosity or a more liberal worldview (as opposed to conservative in a US political context) being more in favor of stronger regulations on nanotechnology. Acceptance of nanotechnology has also been found to be associated with ethical concerns among lay audiences (Davies and Macnaghten 2010; Gupta et al. 2015; Macnaghten 2010). Although studies of the influence of demographic factors are inconclusive, some studies indicate that gender influence risk perception of nanotechnology, with female respondents being more prone to emphasize risk (Bainbridge 2002; Satterfield et al. 2009; Vandermoere et al. 2010).

While public opinion on nanotechnology is relatively easily investigated through surveys distributed to a representative sample of a national population, it is more difficult to study scientists and other experts in the nanotechnology field. Although experts working on nanotechnology-related issues are not a predefined group from which one can easily draw a randomized sample, how scientists and other experts assess nanotechnology risk, their views of nanotechnology, and what influences these attitudes are nevertheless relevant to study. As with research into public opinion, prominent themes are experts' weighing of nanotechnology risk versus benefit, and experts' views of nanotechnology regulation. Studies of experts include studies both of natural scientists specifically working on nanotechnology (Bertoldo et al. 2016; Besley et al. 2008; Chenel et al. 2015; Corley et al. 2009, 2013; Johansson and Boholm 2017; Kim et al. 2012; Powell 2007) and of stakeholders involved in nanotechnology legislation, commercialization, and production (Engeman et al. 2012; Gupta et al. 2012, 2013; Hansen 2010; Tachikawa 2012; van Dijk et al. 2017).

These studies find that experts emphasize nanotechnology benefit over risk (Besley et al. 2008). Van Dijk et al. (2017) demonstrated that risk perception is influenced by the perception of benefit, suggesting that perceived benefit might be offset by perceived risk. Risk is generally rated low, but experts seem to differentiate between environmental risk, risk to human health, and societal risk (Besley et al. 2008). A study of US nanoscientists (Corley et al. 2009) suggests that experts are particularly concerned about the impact of nanotechnology on human health. Benefit is generally emphasized over risk, but the perception of risk and benefit varies depending on the nanotechnology application (Gupta et al. 2012, 2015; van Dijk et al. 2017), that is, whether nanomaterials and nanotechnology are to be used in, for example, cosmetics, medical applications, or food. Research investigating the acceptability of different application areas suggests that several factors influence why some areas are considered more or less beneficial or risky. Van Dijk et al. (2017) found that the acceptability of nanotechnology in different application areas is largely influenced by perceptions of risk and benefit, but also by other factors, such as urgency, anticipated consumer exposure, uncertainties about risk, and trust in industry in the specific field.

Another prevalent theme in the literature on how experts understand nanotechnology is their views of and support for regulation in general and various specific regulatory measures in particular (Besley et al. 2008; Corley et al. 2009, 2013; Kim et al. 2012; Su et al. 2015). A general finding is that respondents emphasizing risk are also more positive toward stronger regulation (Besley et al. 2008; Corley et al. 2009, 2013; Su et al. 2015). Although Corley et al. (2009) hypothesized that respondents who see more benefit from nanotechnology should also be less inclined to support regulation in order to enable development, they did not find a significant correlation between perceived benefit and 
perceived risk. An important factor determining support for regulation among experts is whether the regulations in question are understood to hinder scientific progress (Corley et al. 2013; Su et al. 2015). Other studies examine experts' views of regulation and various regulatory measures. A study of stakeholders in a US regulatory context (Hansen 2010) concluded that there was a relatively high level of alignment between different types of stakeholders, and that they all generally favored a combination of voluntary measures, incrementalism, and a new regulatory framework.

Studies of experts have found that perceived risk and benefit vary with organizational affiliation (Beaudrie et al. 2013; Besley et al. 2008; Corley et al. 2009; Powell 2007). Upstream scientists (i.e., working in laboratories developing nanotechnology) are more likely to emphasize benefit and downplay risk, while downstream scientists (i.e., studying the effects of nanomaterials) do the opposite, emphasizing risk and downplaying benefit (Powell 2007). The disciplinary culture of academic experts influences their risk perception of nanotechnology, as suggested in an ethnographic study of laboratory work (Johansson and Boholm 2017). Differences in attitude are influenced by organizational affiliation, for example, with NGOs, academia, industry, or government (Gupta et al. 2012; Hansen 2010; van Dijk et al. 2017), which can arguably be understood as resulting from the societal role and responsibility of the organization of affiliation (van Dijk et al. 2017). Traditionally, governmental organizations are understood to be responsible for regulation and public health and safety, and environmental NGOs for protecting the environment and human safety, while industry and trade organizations are expected to promote innovation and commercialization (van Dijk et al. 2017). Government and NGO stakeholders, in this line of thought, would be more likely to see risk and less likely to see benefit, and would also more positive toward imposing stronger regulations than would industry stakeholders. Van Dijk et al. (2017) found variability among stakeholders in line with this argument, with experts employed by NGOs having a relatively more negative opinion of nanotechnology than did experts employed by industry.

Some studies have compared expert and lay opinions on nanotechnology (Ho et al. 2011; Gupta et al. 2015; Scheufele et al. 2007; Siegrist et al. 2007; Su et al. 2015). These studies show that experts are generally less inclined to perceive risks and more inclined to emphasize benefits than are laypeople (Ho et al. 2011; Scheufele et al. 2007). Ho et al. (2011) argued that this is due to experts' specialized knowledge in the field, suggesting that high levels of knowledge of nanotechnology are associated with lower perceived risk and higher perceived benefit. However, a US study (Scheufele et al. 2007) demonstrated that experts are more concerned with some risks than is the general public. It has also been demonstrated that experts are less influenced by value predisposition and heuristics than are the public when forming their attitudes toward nanotechnology regulation ( $\mathrm{Su}$ et al. 2015).

Still other studies have shown that experts do rely on heuristics and use normative values when assessing the risks and benefits of nanotechnology and when evaluating regulation. Arguably, this is especially the case when attitudes concern complex and uncertain scientific topics (Silva and Jenkins-Smith 2007). Corley et al. (2009) demonstrated that scientists with liberal political views (as opposed to conservative in an American political context) are more supportive of nanotechnology regulation. Ho et al. (2011) found that trust in science influenced experts' risk judgments, with experts having high trust in science perceiving significantly less risk than do those with low levels of trust. Studies comparing attitudes among the public with those of experts have been criticized for methodological flaws, especially concerning the issue of the representativeness of samples of relevant experts (Ho et al. 2011). Previous studies have been conducted in different countries with differing institutional, cultural, and regulatory contexts. This study contributes to this scholarly debate by studying Swedish experts within the Swedish national and EU regulatory jurisdictions and by comparing the attitudes of experts associated with government organization and industry.

The study is designed to explore the following research hypotheses, developed from previous research into expert stakeholders' positions on nanotechnology.

H1: For the reason that experts in previous studies are less prone to emphasize risk compared to the general public (Ho et al. 2011; Scheufele et al. 2007), we postulate that self-reported knowledge of nanotechnology negatively influences perceived risk.

$\mathrm{H} 2$ : Based on findings in previous research (Besley et al. 2008; Corley et al. 2009, 2013; Su et al. 2015), 
we hypothesize that perceived risk positively influences support for government regulation.

$\mathrm{H} 3$ : Based on previous findings suggesting that nanotechnology is associated with ethical concerns (Davies and Macnaghten 2010; Gupta et al. 2015; Macnaghten 2010), we hypothesize that concern about ethical aspects positively influences support for government regulation.

H4: As government organizations can be understood as responsible for regulations while a primary rationale for the industry is to promote innovation, we hypothesize that government expert stakeholders perceive higher nanotechnology risk and are more inclined to support government regulation than are industry expert stakeholders. This is hypothesis is in line with previous research comparing experts in government and experts in industry regarding nuclear waste management (Jenkins-Smith and Bassett 1994).

\section{Method}

Sample and procedure

This study examines a sample of 237 Swedish expert stakeholders affiliated with government, industry, unions, and civil society engaged in their professional roles with issues concerning nanomaterials and nanotechnology. The sample was obtained by identifying potentially relevant organizations through web searches, reports from government authorities and other organizations, open sources such as lists of participants in conferences and workshops on nanotechnology and nanosafety, and through the established networks of the authors. The aim was to identify and target all relevant stakeholders working professionally on issues relating to nanotechnology in Sweden. Data were collected between January and March 2017 using a web questionnaire survey. Three reminders were sent out, but no incentive was offered.

Of 237 expert stakeholders, 167 completed the survey, for a $70.0 \%$ response rate. Sociodemographic information reported in the questionnaire indicated that $33.3 \%$ of the participants were women and $66.7 \%$ men. The respondents were generally well educated, $55.2 \%$ having a doctoral degree and $39.4 \%$ a bachelor or master's degree. The respondents were educated in various disciplines: $30.3 \%$ in engineering, $29.1 \%$ chemistry, $10.3 \%$ physics, $10.9 \%$ social sciences, $6.1 \%$ toxicology, $3.0 \%$ medicine/pharmacology, $3.0 \%$ biology, $2.4 \%$ environmental sciences, and $4.8 \%$ other disciplinary fields. For some of the analyses in this paper, we isolated two sub-groups of experts, from industry $(n=71)$ and government $(n=59)$. The industry category comprises experts from both business corporations and trade organizations, while the government category comprises experts associated with government authorities, county councils, and other state-owned organizations (excluding universities). The roles in which the experts engage with issues related to nanomaterials and/or nanotechnology are presented in Fig. 1. Multiple entries were possible for each respondent and the results show that they come into contact which issues concerning nanomaterials and nanotechnology in many different ways, including research/research funding, risk assessment, product development, as well as regulation and legislation.

\section{Questionnaire/measures}

The questionnaire contained items addressing perceived risk, perceived benefit, attitude toward regulation, and other items helping explain the drivers of attitudes. The items included in the questionnaire have been developed in relation to previous research on experts' views on nanotechnology (van Dijk et al. 2017; Siegrist et al. 2007). The first page of the questionnaire stated that the survey targeted respondents in their role as experts working on nanotechnology and that the questionnaire would take about $15 \mathrm{~min}$ to complete. Respondents were not required to respond to all items. Initially, the respondents were asked to provide information on gender, organizational affiliation, and educational background.

To measure perceptions of the risks and benefits of nanotechnology, respondents were asked to provide their overall assessments of the risks and benefits of nanotechnology for human health, environment, and society (all rated on five-point scales ranging from $1=$ "Very little risk/benefit" to $5=$ "Very large risk/benefit"). When collapsed, these measures were used as a composite measure of the experts' perceived risk and benefit of nanotechnology. Respondents were also asked to provide information on the perceived benefits and risks of different nanotechnology application areas using fivepoint scales ranging from $1=$ "Very little risk/benefit" to $5=$ "Very large risk/benefit." 


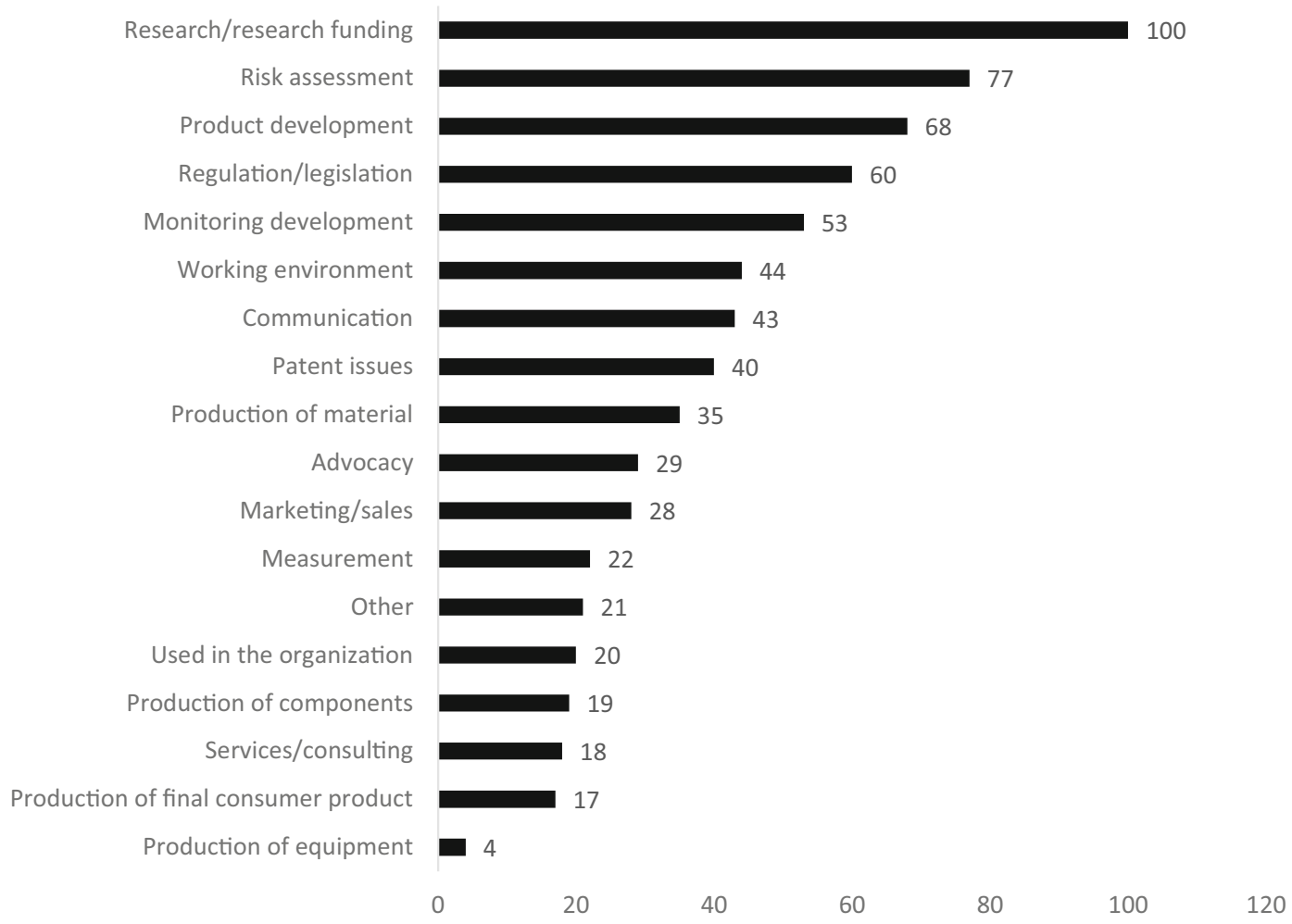

Fig. 1 Role of the respondents in the nanotechnology field (multiple entries were possible for each respondent)

The questionnaire items measuring respondents' attitudes toward various regulatory measures are provided in the footnotes of Table 6. To measure attitudes toward government regulation, participants rated their degree of agreement with the statements in Table 1 using a five-point Likert-type scale ranging from $1=$ "Do not agree at all," through $3=$ "Partly agree," to $5=$ "Totally agree." An acceptably reliable index (Cronbach's $\alpha=.81$ ) was obtained by averaging the reversed coded ratings of the items below, with a high value indicating a positive attitude toward government regulation.

Table 1 Items measuring attitude toward stronger government regulation

The regulation of nanomaterial and nanotechnology is currently fully sufficient.

Companies on their own will be able to develop secure methods to handle nanomaterials.

Companies should be allowed to formulate regulations in their own fields.

Companies know their security needs better than the authorities do.
Respondents were asked to rate their knowledge of nanomaterials on a five-point scale ranging from $1=$ " Very little knowledge" to 5 = "Very great knowledge." The respondents were also asked to rate the relative importance of nanotechnology to their organization on a five-point scale ranging from $1=$ "Very little importance" to $5=$ "Very great importance." Furthermore, the respondents were asked to rate their agreement with the statement "There are ethical concerns associated with the use of nanomaterials and nanotechnologies" on a five-point scale ranging from $1=$ "Do not agree at all" to $5=$ "Totally agree." The respondents were finally asked to state their highest completed level of education. These items were used as independent variables for selfrated knowledge, ethical concern, importance of nanotechnology for the organization, and education.

\section{Results}

Perceived risks and benefits of nanotechnologies

For the entire sample of experts, the variable for risks is $2.75(\mathrm{SD}=0.89)$ and for benefits is $3.73(\mathrm{SD}=0.89)$, 
indicating that benefits were rated higher than risks by the respondents. ${ }^{1}$ There were, however, large variations in the perception of risk and benefit depending on the area of application. Experts' evaluations of the risks and benefits in 11 nanotechnology application areas are presented in Table 2. The mean perceived benefit in all application areas is $3.92(\mathrm{SD}=0.66)$. The greatest overall perceived benefits are for coatings (4.42), electronics (4.42), and materials and material production (4.40), while the lowest are associated with cosmetics and hygiene products (2.60) and agriculture and food (2.71).

There are also large variations in perceived risk between different areas of nanotechnology application (Table 2). The mean perceived risk in all application areas is $2.50(\mathrm{SD}=0.79)$. Experts perceived the lowest risks for measuring instruments and sensors (1.76) and electronics (2.00) and the highest risks for applications in cosmetics and hygiene products (3.30) and agriculture and foods (3.07), the last two application areas being the only ones in which experts rated the risks higher than the benefits.

Perceived benefit might be offset by perceived risk in some areas, as suggested by previous research (Gupta et al. 2015), so respondents might perceive lower benefit because of high perceived risk. As seen in Table 3, however, the only area of nanotechnology application where there is a significant negative correlation between perceived risk and perceived benefit is cosmetics and hygiene products. In all the other application areas, other factors determine the expert stakeholders' evaluation of benefit. Possible explanations as to why some areas were considered more or less beneficial will be addressed in the discussion section.

\section{Drivers of perceived nanotechnology risk and benefit}

To investigate the drivers of the perceived risk of nanotechnology, we conducted a hierarchical ordinary least square multivariate regression using perceived risk as the dependent variable. The independent variables were entered in two blocks: the first block consisted of the sociodemographic variables gender and education, while the second block consisted of the sociodemographic variables and experts' self-rated knowledge of nanotechnology,

\footnotetext{
${ }^{1}$ These variables comprise the collapsed value of respondents' overall assessments of the risks and benefits of nanotechnology for human health, environment, and society (all rated on five-point Likert-type scales), as described in the method section.
}

importance of nanotechnology for the organization, ethical concern, and perceived benefit. As seen in Table 4, sociodemographic variables had no influence on expert perceptions of the risk associated with nanotechnology. Furthermore, risk perception was not influenced by how important nanotechnology was in the respondent's organization of affiliation, nor was it influenced by the respondents' self-reported knowledge, so Hypothesis 1 must be rejected. The only investigated variables that influenced perceived risk were experts' ethical concern with nanotechnology $(\beta=0.34, p<.001)$ and perceived benefit $(\beta=$ $0.18, p<.05)$. The results indicate that ethical concerns about nanotechnology use increased the perceived risk of nanotechnology, while high perceived benefit had an opposite effect on perceived risk. Altogether, however, these variables explain only a marginal part of the variance in perceived risk $\left(r^{2}=0.16\right)$.

Similarly to perceived risk, the drivers of experts' perceived benefit of nanotechnology were studied by regressing the same variables as above, except that perceived benefit instead of perceived risk was introduced as an independent variable (Table 5). As in the previous regression, sociodemographic variables had no influence on the dependent variable. The only investigated variables that influenced experts' perceived benefit of nanotechnology was importance of nanotechnology for the organization $(\beta=0.38$, $p<.001$ ), showing that respondents were more likely to emphasize the perceived benefit if nanotechnology was relatively more important for their organizations. Altogether, these variables explain only a modest proportion of the variance in experts' perceived benefit of nanotechnology $\left(r^{2}=0.10\right)$.

Experts' attitudes toward different regulatory measures and the drivers of attitudes toward stronger regulation

As shown in Table 6, about $83 \%$ of experts partly or fully endorsed further regulations, while only about $4 \%$ strongly opposed them. In other words, the general attitude of the respondents was that current nanomaterial and nanotechnology regulations were insufficient. However, as seen in Table 6 , the support for different regulatory measures varied. There was relatively strong support for selective bans, with about $73 \%$ of experts agreeing partly or fully with the statement "Certain nanomaterials should be banned entirely," although 14 experts strongly disagreed with selective bans as an applicable regulatory measure. Labeling as a regulatory measure divided expert 
Table 2 Perceived benefit and risk of nanomaterials and nanotechnology in different application areas

\begin{tabular}{|c|c|c|c|c|c|}
\hline Area of application & $\begin{array}{l}\text { Perceived } \\
\text { benefit }^{a}\end{array}$ & $\begin{array}{l}\text { Standard } \\
\text { deviation }\end{array}$ & $\begin{array}{l}\text { Perceived } \\
\text { risk }^{b}\end{array}$ & $\begin{array}{l}\text { Standard } \\
\text { deviation }\end{array}$ & $\begin{array}{l}\text { Difference between } \\
\text { perceived benefit and risk }^{c}\end{array}$ \\
\hline Medicine and medical care & 4.13 & 0.81 & 2.37 & 0.89 & 1.76 \\
\hline $\begin{array}{l}\text { Environmental and energy } \\
\text { technology }\end{array}$ & 3.94 & 0.97 & 2.32 & 1.02 & 1.62 \\
\hline $\begin{array}{l}\text { Measuring instruments } \\
\text { and sensors }\end{array}$ & 4.28 & 0.76 & 1.76 & 0.73 & 2.52 \\
\hline Cosmetics and hygiene products & 2.60 & 1.10 & 3.30 & 1.07 & -0.70 \\
\hline Agriculture and food & 2.71 & 0.96 & 3.07 & 1.06 & -0.36 \\
\hline Packaging & 3.34 & 1.15 & 2.32 & 0.96 & 1.02 \\
\hline Electronics & 4.42 & 0.81 & 2.00 & 0.87 & 2.42 \\
\hline Coatings & 4.42 & 0.74 & 2.41 & 1.02 & 2.01 \\
\hline $\begin{array}{l}\text { Materials and material } \\
\text { production }\end{array}$ & 4.40 & 0.78 & 2.52 & 0.99 & 1.88 \\
\hline Catalysts and filters & 4.36 & 0.76 & 2.24 & 0.91 & 2.12 \\
\hline Paint & 3.95 & 0.88 & 2.76 & 1.05 & 1.19 \\
\hline Total & 3.92 & 0.66 & 2.50 & 0.79 & 1.42 \\
\hline
\end{tabular}

${ }^{a}$ Experts' ratings of the benefits of different areas of nanotechnology application were assessed using a five-point Likert-type scale

${ }^{b}$ Experts' ratings of the risks of different areas of nanotechnology application were assessed using a five-point Likert-type scale

${ }^{\mathrm{c}}$ This figure is the variable for perceived benefit minus the variable for perceived risk, with a positive number indicating that perceived benefit exceeds perceived risk

opinion, with 35 experts strongly disagreeing with this regulatory tool and 27 experts strongly agreeing. There was low support for self-regulation as a regulatory measure, and when it came to taxation, there was agreement among most experts that taxes were ineffective or inappropriate.

Table 3 Correlation between perceived benefit and perceived risk in the different areas of nanotechnology application

\begin{tabular}{lcl}
\hline Area of application & $\begin{array}{l}\text { Pearson } \\
\text { correlation }\end{array}$ & $\begin{array}{l}\text { Sig. } \\
\text { (two-tailed) }\end{array}$ \\
\hline Medicine and medical care & -0.016 & 0.865 \\
Environmental and energy technology & 0.032 & 0.760 \\
Measuring instruments and sensors & 0.000 & 1.000 \\
Cosmetics and hygiene products & -0.379 & $0.000^{* *}$ \\
Agriculture and food & -0.213 & $0.053^{\dagger}$ \\
Packaging & -0.179 & 0.114 \\
Electronics & -0.175 & $0.083^{\dagger}$ \\
Coatings & -0.092 & 0.331 \\
Materials and material production & -0.037 & 0.706 \\
Catalysts and filters & -0.072 & 0.512 \\
Paint & 0.002 & 0.987 \\
\hline
\end{tabular}

${ }^{\dagger} p<0.1 ; * * p<0.01$
To investigate what drives experts' attitudes toward stronger governmental nanotechnology regulations, a hierarchical multivariate regression analysis was conducted with attitude to stronger government regulation as the dependent variable (specifically, using the indexed value of support for government regulation as described in the "Method" section as the dependent variable). The independent variables were the same as in the previous hierarchical regressions and were entered in two blocks: the first block consisted of the sociodemographic variables

Table 4 Hierarchical regression with perceived risk as the dependent variable

\begin{tabular}{lcc}
\hline Variables & Model 1 & Model 2 \\
\hline Gender & -0.11 & -0.08 \\
Education & -0.04 & 0.03 \\
Self-rated knowledge & & -0.07 \\
Importance of nanotechnology & & -0.16 \\
$\quad$ for the organization & & $0.34 * * *$ \\
Ethical concern & & $-0.18 *$ \\
Perceived benefit & $<1 \%$ & $16.3 \%$ \\
Total & & \\
\hline
\end{tabular}

${ }^{*} p<0.05 ; * * * p<0.001$ 
Table 5 Hierarchical regression with perceived benefit as the dependent variable

\begin{tabular}{lcc}
\hline Variables & Model 1 & Model 2 \\
\hline Gender & 0.13 & 0.07 \\
Education & -0.01 & -0.06 \\
Self-rated knowledge & & -0.03 \\
Importance of nanotechnology & & $0.38 * * *$ \\
$\quad$ for the organization & & 0.04 \\
Ethical concern & & $-0.16^{\dagger}$ \\
Perceived risk & $<1 \%$ & $10.0 \%$ \\
Total & & \\
${ }^{\dagger} p<0.1 ; * * *<0.001$ & &
\end{tabular}

gender and education, while the second consisted of the sociodemographic variables as well as self-rated knowledge, importance of nanotechnology for the organization, ethical concern, as well as the perceived benefit and perceived risk of nanotechnology. The sociodemographic variables in the first block had no influence on experts' attitudes toward further regulation of nanotechnology. In the second block, importance of nanotechnology for the organization $(\beta=0.21, p<.05)$, ethical concern $(\beta=$ $0.21, p<.01)$, perceived risk $(\beta=0.33, p<.001)$, and perceived benefit $(\beta=0.15, p<.05)$ together explained a significant part of the variance in experts' attitudes toward further regulation $\left(r^{2}=24.1\right)$. The variables ethical concern and perceived risk of nanotechnology were positively related to attitude toward government regulations, so that respondents were more in favor of government regulation if they understood nanotechnology use to be associated with risk and with ethical considerations; consequently, Hypotheses 2 and 3 were confirmed. If nanotechnology was important for the respondent's organization of affiliation, there was less inclination to support government regulations. High perceived benefit also decreased the support for government regulation (Table 7).

Attitudinal gap between government experts and industry experts

To investigate the importance of organizational affiliation for experts' assessments of nanotechnology benefit and risk and for their attitude toward regulation, we isolated two important groups of experts from the sample, namely, government experts and industry experts. As revealed in, the value of the variable attitudes toward stronger government regulations was $2.50(\mathrm{SD}=0.84)$ for industry experts and $3.00(\mathrm{SD}=0.55)$ for government experts, meaning that experts working in government organizations more strongly supported government regulations than did experts in industry ( $t=$ - 3.94, $d f=129, p<.001$ ), confirming Hypothesis 4 . Moreover, experts affiliated with government had

Table 6 Experts' attitudes toward different nanotechnology regulatory measures

\begin{tabular}{|c|c|c|c|c|c|c|c|c|c|}
\hline & $n$ & Mean & SD & 1 & 2 & 3 & 4 & 5 & Balance $^{f}$ \\
\hline Regulation is insufficient $t^{\mathrm{a}}$ & 154 & 3.66 & 1.14 & 6 & 20 & 39 & 44 & 45 & 40.9 \\
\hline Self-regulation ${ }^{\mathrm{b}}$ & 156 & 2.01 & 1.02 & 61 & 48 & 36 & 7 & 4 & -62.8 \\
\hline Labeling $^{\mathrm{c}}$ & 155 & 2.90 & 1.39 & 35 & 27 & 37 & 30 & 26 & -3.9 \\
\hline Selective bans ${ }^{\mathrm{d}}$ & 151 & 3.40 & 1.31 & 14 & 27 & 35 & 34 & 41 & 22.5 \\
\hline Taxation $^{\mathrm{e}}$ & 149 & 1.53 & 0.85 & 95 & 36 & 14 & 1 & 3 & -85.2 \\
\hline
\end{tabular}

${ }^{a}$ This variable is the reverse coded value of the response to the statement "The regulation of nanomaterials and nanotechnology today is fully sufficient" ( 1 = strongly disagree, 5 = strongly agree $)$

b This variable is the value of the response to the statement "Companies should be responsible for formulating regulations in their field of business" ( 1 = strongly disagree, 5 = strongly agree $)$

${ }^{\mathrm{c}}$ This variable is the value of the response to the statement "Mandatory labeling of all products containing nanomaterials and nanoparticles should be required" ( $1=$ strongly disagree, $5=$ strongly agree $)$

d This variable is the value of the response to the statement "Certain nanomaterials and nanoparticles should be banned entirely in products" ( 1 = strongly disagree, $5=$ strongly agree $)$

${ }^{\mathrm{e}}$ This variable is the value of the response to the statement "Excise taxes are an appropriate way of controlling the risks of nanomaterials and nanotechnologies" ( 1 = strongly disagree, 5 = strongly agree $)$

${ }^{\mathrm{f}}$ The balance value is the percentage of respondents who chose one of the two lowest values, minus the percentage of respondents who chose one of the two highest values. In other words, the balance value is a number between -100 and 100 . A strongly positive number indicates a generally supportive attitude, whereas a strongly negative number indicates low general support for the regulatory measure 
Table 7 Hierarchical regression with attitude toward stronger government regulations as the dependent variable

\begin{tabular}{lrc}
\hline Variables & Model 1 & Model 2 \\
\hline Gender & -0.15 & -0.06 \\
Education & 0.03 & 0.07 \\
Self-rated knowledge & & 0.06 \\
Importance of nanotechnology & & $-0.21^{*}$ \\
$\quad$ for the organization & & $0.21^{* *}$ \\
Ethical concern & $0.33^{* * *}$ \\
Perceived risk & & $-0.15^{*}$ \\
Perceived benefit & $<1 \%$ & $24.1 \%$ \\
Total & & \\
\hline
\end{tabular}

$* p<0.05 ; * * p<0.01 ; * * * p<0.001$

stronger ethical concerns and perceived higher risks than did experts in industry, while experts in industry rated both their knowledge and the importance of nanotechnology for their organizations higher. However, both groups of experts had similar levels of education and there were no significant differences in the perception of nanotechnology benefits (Table 8).

\section{Discussion}

Perceived risks and benefits of nanotechnology and nanotechnology applications

This study has demonstrated that the studied Swedish stakeholders generally had a positive attitude toward nanotechnology and that the stakeholders emphasized the benefits of nanotechnology over the risks. This finding is aligned with previous studies of the perception of nanotechnology (Besley et al. 2008). In line with previous research (Gupta et al. 2012, 2015; van Dijk et al. 2017), this study found large differences in attitudes depending on the area of nanotechnology use. Although respondents were positive toward most nanotechnology applications, the perceived risk exceeded the perceived benefit for use in the application areas cosmetics and hygiene products and in agriculture and food. This result indicates that benefits do not always outweigh risks in the view of experts. Previous research has shown that experts are more positive toward nanotechnology use in medicine than in foods (van Dijk et al. 2017); similarly, this study found that Swedish expert stakeholders viewed applications in medicine as more beneficial and less risky than applications in food. There were substantial differences in the perceived risks and benefits between the different application areas.

The application areas considered most beneficial were electronics, coatings, and materials and material production and the areas considered least beneficial were cosmetics and hygiene products, agriculture and food, and packing. It can be assumed that several factors influence how expert stakeholders evaluate the benefit of nanotechnology in each application area. As discussed regarding previous research, perceived benefit might be offset by high perceived risk (Gupta et al. 2015). However, this can only partly explain the risk perception for applications in cosmetics. It is reasonable to assume that perceived benefit is influenced by how beneficial the area of application is considered for society at large. This might be why nanotechnology applications in medicine are rated as more beneficial than

Table 8 Differences between government experts and industry experts ( $t$ test with means and standard deviations in parentheses)

\begin{tabular}{llll}
\hline Variables & Government $(n=59)$ & Industry $(n=71)$ & $1.65(0.48)$ \\
\hline Gender & $1.60(0.49)$ & $63.3 \%$ & -0.57 \\
$\%$ Male & $60.3 \%$ & $4.48(0.73)$ & 0.52 \\
Education & $4.56(0.68)$ & $47.9 \%$ & $3.10(1.11)$ \\
$\%$ PhD degree & $57.9 \%$ & $3.14(1.27)$ & $-1.99 *$ \\
Self-rated knowledge & $2.73(0.98)$ & $2.44(1.18)$ & $-3.52 * * *$ \\
Importance of nanotechnology for the organization & $2.42(1.00)$ & $3.02(1.31)$ & $2.13 *$ \\
Ethical concern & $2.91(1.18)$ & $4.05(1.03)$ & $2.07 *$ \\
Perceived risk & $3.52(1.41)$ & $2.50(0.84)$ & $3.94 * * *$ \\
Perceived benefit & $3.92(0.94)$ & $3.00(0.55)$ & \\
Attitude to stronger government regulation & & & \\
\hline
\end{tabular}

$* p<0.05 ; * * p<0.01 ; * * * p<0.001$ 
applications in cosmetics. It is also reasonable to assume that existing well-functioning nanotechnology products in a specific application area would make experts more likely to emphasize benefits in that area. This might explain why nanotechnology use in medicine is considered less beneficial than its use in coatings, materials and material production, and electronics: there are already existing nanotechnology applications in these fields, while there are few such applications in medicine and medical care and little commercialization due to the strict regulation of drugs and medical applications (Larsson et al. 2017).

As shown in the "Results" section, there were also large differences in risk perception depending on the field of nanotechnology application. The respondents associated greater risk with applications in cosmetics and hygiene products, agriculture and food, and paint, and lower risk with applications in measuring instruments and sensors, electronics, and catalysts and filters. Why respondents have different risk perceptions for different fields of application might have several explanations. As a large majority of the experts had natural science backgrounds, it is plausible that perceived toxicity and anticipated exposure to nanomaterials used in a specific field of application might influence their risk perception. From this perspective, applications in electronics can be understood as less risky than applications in cosmetics, where diffusion of nanomaterials into the environment is harder to control. The three application areas considered most risky, i.e., agriculture and food, cosmetics and hygiene products, and paint, are application areas that potentially involve bodily exposure, and are areas where relatively large quantities of nanoparticles would be used, with a higher probability of crossover into the environment. As suggested by previous research (van Dijk et al. 2017), a negative view of a specific field of nanotechnology application might be affected by factors such as low urgency or lack of trust in actors in a specific field. Additional research is needed to explain how expert stakeholders form their judgments of different fields of nanotechnology application, and whether or not the acceptability of using nanotechnology in different application areas diverge from the acceptability of utilizing other new technologies within these same application areas.

Drivers of perceived risk and perceived benefit

What factors influenced the Swedish expert stakeholders' general attitude toward the benefits and risks of nanotechnology, and are these factors aligned with previous research? As demonstrated here, general perceived risk was influenced by the perceived benefit, meaning that respondents who were more inclined to perceive benefit were less inclined to perceive risk, a result in agreement with previous research (Gupta et al. 2015). Risk perception is influenced by ethical concerns, and respondents inclined to have ethical concerns with nanotechnology were more likely to perceive risk, also a result in agreement with previous research (Gupta et al. 2015). This is unsurprising, and ethical considerations can very well include risk awareness, and nanotechnology might then become an ethical problem due to associated risk.

Risk perception among the respondents was not influenced by the demographic factors gender or education level. Although previous research is inconclusive when it comes to the influence of demographic factors on the attitudes to nanotechnology some previous studies of the perception of nanotechnology have identified gender differences in risk perception (Vandermoere et al. 2010), though we found no such effects when it came to assessing nanotechnology risk. A possible explanation is that demographic factors such as gender are more influential on attitudes among the general public compared to the attitudes of experts.

Self-rated knowledge of nanotechnology did not influence risk perception among the Swedish experts although experts with a high level of knowledge are generally less inclined to perceive risk than are members of the general public with a low level of knowledge (Ho et al. 2011; Scheufele et al. 2007). Our study also demonstrated that the relative importance of nanotechnology for the respondent's organization of affiliation did not affect risk perception. Our finding that neither knowledge nor proximity (defined as the importance of nanotechnology for the organization) affected risk perception stands in contrast to previous research in risk psychology, which have demonstrated that knowledge of and proximity to a certain technological area generally gives a higher sense of control and consequently a lower risk perception (Slovic 2000).

That neither knowledge nor proximity influenced risk perception might be because nanotechnology and nanomaterials encompass such a wide range of applications that knowledge of nanotechnology in one application area might not translate into knowledge in other such areas. The finding that knowledge of nanotechnology and nanomaterials did not affect perceived risk does not mean 
that experts do not rely on their professional knowledge or on scientific methods in assessing risk in their areas of expertise, but that high knowledge in one area of nanotechnology in particular does not automatically imply greater acceptability of nanotechnology in general.

As with general perceived risk, general perceived benefit was not influenced by gender, education level, or self-rated knowledge. Unlike perceived risk, perceived benefit was not influenced by ethical concerns. Also unlike perceived risk, benefit was influenced by the importance of nanotechnology for the respondent's organization of affiliation. It is perhaps unsurprising that experts, especially in industry, were more likely to emphasize benefits if nanotechnology was important for their organizations.

Attitude toward different regulatory measures, and drivers of support for government regulations

This study demonstrated that Swedish expert stakeholders were generally supportive of the regulation of nanomaterials and nanotechnology, with a majority claiming that current regulation is insufficient (Table 6). Selective bans were preferred to taxation and self-regulation. The high support for selective bans indicates that experts saw some nanomaterials as potentially dangerous, and that it might be necessary to introduce selective prohibitions to protect human health and the environment from specific nanomaterials, without affecting the production and use of other nanomaterials. The low support for self-regulation as a regulatory measure indicates agreement that industry alone cannot be responsible for regulation and safety measures. Labeling as a regulatory measure seemed to divide the experts: many were supportive, but many opposed labeling as an appropriate regulatory measure. The benefit of labeling is that it allows consumers to make choices, though mandatory labeling might cement the impression of nanotechnology as something dangerous to be avoided (Larsson et al. 2017).

What influences Swedish expert stakeholders' support for government regulations? This study has shown that the general attitude toward regulation is influenced by perceived risk: If a respondent perceives greater risk, he or she is more inclined to support stronger regulation, a result aligned with previous research (Besley et al. 2008; Corley et al. 2009, 2013; Su et al. 2015). A likely explanation is that stakeholders more likely to perceive risk are more supportive of regulation to prevent dangerous pollution and exposure. This study has also identified a small but significant correlation between perceived benefit and attitude toward regulation, with respondents who see greater benefit also being less inclined to support the regulation of nanotechnology. A possible explanation is that respondents with a positive attitude toward nanotechnology want less regulation in order to facilitate innovation and commercialization. Other factors that influence support for government regulation are ethical concerns and the importance of nanotechnology for the respondent's organization of affiliation. If nanotechnology is important for their organizations, experts are less positive toward regulation, while ethical concern has the opposite influence on support for government regulation.

\section{Differences depending on organizational affiliation}

This study has identified significant differences between stakeholders associated with government versus industry organizations. We conjectured that experts' attitudes toward the regulation of nanomaterials would be influenced by the organizational context in which they work, as different societal organizations have different roles and responsibilities and follow different institutional logics (Apostolakis and Pickett 1998; Jenkins-Smith and Bassett 1994). Although all such experts share a concern for the safe development of useful products, experts working in government organizations are traditionally understood to be responsible for risk assessment and regulation, and can thus be expected to be more concerned with the risks and ethical implications of nanotechnology and more inclined to support government regulations (van Dijk et al. 2017).

In contrast, experts working in industry are primarily concerned with innovation and the commercialization of nanotechnology and nanomaterials, and can be expected to be less inclined to emphasize risk and ethical concerns, and less supportive of government regulation (van Dijk et al. 2017). In line with this logic, we identified variability in the sample of Swedish experts, with government experts being more inclined to emphasize risk and ethical concerns. Support for government regulation was also affected by whether or not the respondent was affiliated with government or industry, with experts in government being more likely to emphasize the need for further regulation. These results can be understood as aligned with the different concerns and societal roles of the different groups of stakeholders. According to the 
same logic, industry experts might be expected to emphasize benefits more than do government experts, though no such pattern was identified here.

\section{Policy implications}

Nanotechnology is a knowledge-intensive field, and government or individual industry actors lack the capacity to conduct risk assessments and ensure the safe development of nanotechnology products. The establishment of trustworthy, legitimate, and effective governance frameworks for the regulation of nanomaterials arguably demands inter-institutional and inter-organizational collaboration among a broad range of societal actors (Bosso 2016). Expert stakeholders consequently can be expected to play an important role in developing the safe management and regulation of nanotechnology (Hansen 2010). Successful cooperation between actors will require at least partial agreement on the problem definition and characterization, and some shared definitions of specific concepts. This study contributes to such knowledge on stakeholder expert's agreement and disagreement in views of nanotechnology.

This study found relatively strong overall support for regulation, although industry stakeholders were less likely to support stronger regulations and less likely to emphasize risk, while both industry and government stakeholders had similar views of the benefits of nanotechnology. It is of interest to know how expert stakeholder view different regulatory measures. Expert stakeholders viewed self-regulation by industry as insufficient, while selective bans were considered an appropriate regulatory measure. The experts were divided in their views of labeling as an appropriate regulatory measure to ensure nanosafety. Taxation was considered inadequate for regulating nanotechnology.

Furthermore, the study found that experts' attitudes toward risk were influenced by perceived benefit, and that the specific area of application was important for how experts assessed risk versus benefit. More research is needed to explore how organizational affiliation, goals, and orientation influence expert stakeholders' perception of the risks and benefits of nanotechnology, and what regulatory tools and measures they prefer and why. A policy implication of the study is that arenas for dialog and the cross-fertilization of the knowledge, perspectives, and views of different stakeholder groups are needed. This has been said many times before (Shatkin et al. 2010), but the message is still relevant if nanotechnology is to be developed responsibly with the support of society at large.

Limitations

A limitation of this study is that the selection of respondents was not randomized. As discussed above, there is no given population of nanotechnology experts from which a random sample could be drawn. The aim was to include all organizations and experts currently engaged with issues concerning nanotechnology. As argued by Besley et al. (2008), such a sampling procedure makes the most sense for a specialized population such as that explored here, although it is not technically a sample. Even though some organizations and potentially relevant experts are missing and it is difficult to analyze the potentially missing actors, the sample includes a large part of the current community of expert stakeholders in the nano-field, comprising stakeholders from 161 Swedish organizations.

\section{Conclusions}

The overarching aim of this study was to investigate Swedish expert stakeholders' perceptions of nanotechnology risks and benefits and their attitudes toward the regulation of nanotechnology. The main findings are summarized in this brief conclusion. The study has demonstrated that self-rated knowledge among the experts did not affect perception of risk or benefit, or support for government regulation; gender and education level did not influence perceived benefit, perceived risk, or support for government regulation.

If nanotechnology was important for the respondent's organization of affiliation, there was a tendency to emphasize benefits and less inclination to support government regulation, though the importance of nanotechnology for the organization did not influence risk perception. Perceived risk was increased by ethical concerns and decreased by perceived benefit. Industry respondents were less inclined to perceive risk and less supportive of government regulations, but there was no significant difference in the perceived benefit of nanotechnology between government and industry expert stakeholders. The general perceived benefit outweighed perceived risk in the entire sample of respondents.

The perceived risk and benefit depended on the specific application area: the areas considered most 
beneficial by respondents were electronics and coatings, while the areas considered most risky were cosmetics and hygiene products and agriculture and food. The areas perceived as most beneficial were those with existing applications of nanotechnology. The application areas considered risky share high potential bodily exposure and use of large quantities of nanoparticles with the possibility of the crossover of nanoparticles into the environment.

Most of the expert stakeholders favored stronger governmental regulations. They had a positive attitude toward selective bans but a negative attitude toward self-regulation and taxation as regulatory measures for ensuring the safe use of nanomaterials and nanotechnology. Labeling as a regulatory measure divided the experts. High perceived benefit decreased support for government regulation, while high perceived risk and ethical concerns increased support for government regulations.

Acknowledgments This research has been founded by The Swedish foundation for strategic environmental research (MISTRA) and the Swedish Research Council (Vetenskapsrådet). We would like to thank the anonymous reviewers for valuable comments.

\section{Compliance with ethical standards}

Conflict of interest The authors declare that they have no conflict of interest.

Open Access This article is distributed under the terms of the Creative Commons Attribution 4.0 International License (http:// creativecommons.org/licenses/by/4.0/), which permits unrestricted use, distribution, and reproduction in any medium, provided you give appropriate credit to the original author(s) and the source, provide a link to the Creative Commons license, and indicate if changes were made.

\section{References}

Anderson B (2007) Hope for nanotechnology: anticipatory knowledge and the governance of affect. Area 39(2):156-165. https://doi.org/10.1111/j.1475-4762.2007.00743.x

Apostolakis GE, Pickett SE (1998) Deliberation: integrating analytical results into environmental decisions involving multiple stakeholders. Risk Anal 18(5):621-634. https://doi. org/10.1111/j.1539-6924.1998.tb00375.x

Bainbridge WS (2002) Public attitudes toward nanotechnology. J Nanopart Res 4(6):561-570. https://doi.org/10.1023 /A:10228055
Beaudrie CE, Kandlikar M, Satterfield T (2013) From cradle-tograve at the nanoscale: gaps in US regulatory oversight along the nanomaterial life cycle. Environ Sci Technol 47(11): 5524-5534. https://doi.org/10.1021/es303591x

Bertoldo R, Mays C, Poumadère M, Schneider N, Svendsen C (2016) Great deeds or great risks? Scientists' social representations of nanotechnology. J Risk Res 19(6):760-779. https://doi.org/10.1080/13669877.2015.1042503

Besley JC (2010) Current research on public perceptions of nanotechnology. Emerg Health Threat J 3(1):7098. https://doi. org/10.3402/ehtj.v3i0.7098

Besley JC, Kramer VL, Priest SH (2008) Expert opinion on nanotechnology: risks, benefits, and regulation. J Nanopart Res 10: 549-558. https://doi.org/10.1007/s11051-007-9323-6

Boholm M, Arvidsson R (2016) A definition framework for the terms nanomaterial and nanoparticle. NanoEthics 10(1):2540. https://doi.org/10.1007/s11569-015-0249-7

Bosso C (2016) Settling into the midstream? Lessons for governance from the decade of nanotechnology. J Nanopart Res 18(6):163. https://doi.org/10.1007/s11051-016-3451-9

Brossard D, Scheufele DA, Kim E, Lewenstein BV (2009) Religiosity as a perceptual filter: examining processes of opinion formation about nanotechnology. Public Underst Sci 18(5):546-558. https://doi.org/10.1177/0963662507087304

Buxton L (2018) Small things are finally in REACH. Chemical Watch: Global Risk and Regulation News. https://chemicalwatch. com/67610/small-things-are-finally-in-reach. Accessed 1 October 2018

Cacciatore MA, Scheufele DA, Corley EA (2011) From enabling technology to applications: the evolution of risk perceptions about nanotechnology. Public Underst Sci 20(3):385-404. https://doi.org/10.1177/0963662509347815

Chenel V, Boissy P, Cloarec JP, Patenaude J (2015) Effects of disciplinary cultures of researchers and research trainees on the acceptability of nanocarriers for drug delivery in different contexts of use: a mixed-methods study. J Nanopart Res 17(4):186. https://doi.org/10.1007/s11051-015-2998-1

Corley EA, Scheufele DA, Hu Q (2009) Of risks and regulations: how leading US nanoscientists form policy stances about nanotechnology. J Nanopart Res 11(7):1573-1585. https://doi.org/10.1007/s11051-009-9671-5

Corley EA, Kim Y, Scheufele DA (2011) Public challenges of nanotechnology regulation. Jurimetrics 52:371

Corley EA, Kim Y, Scheufele DA (2013) The current status and future direction of nanotechnology regulations: a view from nano-scientists. Rev Policy Res 30(5):488-511. https://doi. org/10.1111/ropr.12036

Davies SR, Macnaghten P (2010) Narratives of mastery and resistance: lay ethics of nanotechnology. NanoEthics 4(2): 141-151. https://doi.org/10.1007/s11569-010-0096-5

Engeman CD, Baumgartner L, Carr BM, Fish AM, Meyerhofer JD, Satterfield TA, Holden PA, Harthorn BH (2012) Governance implications of nanomaterials companies' inconsistent risk perceptions and safety practices. J Nanopart Res 14(3):749. https://doi.org/10.1007/s11051-012-0749-0

Fadeel B, Pietroiusti A, Shvedova AA (eds) (2017) Adverse effects of engineered nanomaterials: exposure, toxicology, and impact on human health. Academic Press, London

Gaskell G, Eyck TT, Jackson J, Veltri G (2005) Imagining nanotechnology: cultural support for technological innovation in 
Europe and the United States. Public Underst Sci 14(1):8190. https://doi.org/10.1177/0963662505048949

Grieger KD, Baun A, Owen R (2010) Redefining risk research priorities for nanomaterials. J Nanopart Res 12(2):383-392. https://doi.org/10.1007/s11051-009-9829-1

Gupta N, Fischer AR, van der Lans IA, Frewer LJ (2012) Factors influencing societal response of nanotechnology: an expert stakeholder analysis. J Nanopart Res 14(5):857. https://doi. org/10.1007/s11051-012-0857-x

Gupta N, Fischer AR, George S, Frewer LJ (2013) Expert views on societal responses to different applications of nanotechnology: a comparative analysis of experts in countries with different economic and regulatory environments. J Nanopart Res 15(8):1838. https://doi.org/10.1007/s11051-013-1838-4

Gupta N, Fischer AR, Frewer LJ (2015) Ethics, risk and benefits associated with different applications of nanotechnology: a comparison of expert and consumer perceptions of drivers of societal acceptance. Nanoethics 9(2):93-108. https://doi. org/10.1007/s11569-015-0222-5

Hansen SF (2010) Multicriteria mapping of stakeholder preferences in regulating nanotechnology. J Nanopart Res 12(6): 1959-1970. https://doi.org/10.1007/s11051-010-0006-3

Hansen SF, Baun A (2012) European regulation affecting nanomaterials-review of limitations and future recommendations. Dose-Response 10(3). https://doi.org/10.2203/doseresponse.10-029.Hansen

Hartmanis Å (2013) Nanoteknik för hållbar samhällsutveckling: Slutrapport för Vinnovaprojekt 2012-01866, Strategisk forsknings- och innovationsagenda. SwedNanoTech, Stockholm

Ho SS, Scheufele DA, Corley EA (2010) Making sense of policy choices: understanding the roles of value predispositions, mass media, and cognitive processing in public attitudes toward nanotechnology. J Nanopart Res 12(8):2703-2715. https://doi.org/10.1007/s11051-010-0038-8

Ho SS, Scheufele DA, Corley EA (2011) Value predispositions, mass media, and attitudes toward nanotechnology: the interplay of public and experts. Sci Commun 33(2):167-200. https://doi.org/10.1177/1075547010380386

Jenkins-Smith H, Bassett GW (1994) Perceived risk and uncertainty of nuclear waste: differences among science, business, and environmental group members. Risk Anal 14(5):851856. https://doi.org/10.1111/j.1539-6924.1994.tb00297.x

Johansson M, Boholm $\AA$ (2017) Scientists' understandings of risk of nanomaterials: disciplinary culture through the ethnographic lens. Nanoethics 11(3):229-242. https://doi. org/10.1007/s11569-017-0297-2

Kim Y, Corley EA, Scheufele DA (2012) Classifying US nanoscientists: of cautious innovators, regulators, and technology optimists. Sci Public Policy 39(1):30-38. https://doi. org/10.3152/030234212X13113405157822

Kim J, Yeo SK, Brossard D, Scheufele DA, Xenos MA (2014) Disentangling the influence of value predispositions and risk/ benefit perceptions on support for nanotechnology among the American public. Risk Anal 34(5):965-980. https://doi. org/10.1111/risa.12141

Larsson S, Boholm $\AA$ (2018) Den svenska allmänhetens inställning till nanoteknik. In: Andersson U, Carlander A, Lindgren E, Oskarson M (eds) Sprickor i fasaden. Göteborgs universitet: SOM-institutet, Gothenburg, pp 293-303
Larsson S, Boholm A, Jansson M (2017) Attitudes towards nanomaterials and nanotechnology among Swedish expert stakeholders: risk, benefit and regulation. GRI Report Series, No. 2017: 2

Lee CJ, Scheufele DA, Lewenstein BV (2005) Public attitudes toward emerging technologies: examining the interactive effects of cognitions and affect on public attitudes toward nanotechnology. Sci Commun 27(2):240-267. https://doi. org $/ 10.1177 / 1075547005281474$

Macnaghten P (2010) Researching technoscientific concerns in the making: narrative structures, public responses, and emerging nanotechnologies. Environ Plan A 42(1):23-37. https://doi. org/10.1068/a41349

Miller G, Wickson F (2015) Risk analysis of nanomaterials: exposing Nanotechnology's naked emperor. Rev Policy Res 32(4):485-512. https://doi.org/10.1111/ropr.12129

Organisation for Economic Co-operation and Development (OECD) (2012) Important issues on risk assessment of manufactured nanomaterials. Series on the safety of manufactured nanomaterials, Number 33

Organisation for Economic Co-operation and Development (OECD) (2013) Co-operation on risk assessment: Prioritisation of important issues on risk assessment of manufactured nano materials - final report. Series on the Safety of Manufactured Nanomaterials, Number 38

Pidgeon N, Harthorn BH, Bryant K, Rogers-Hayden T (2009) Deliberating the risks of nanotechnologies for energy and health applications in the United States and United Kingdom. Nat Nanotechnol 4(2):95-98. https://doi. org/10.1038/nnano.2008.362

Powell MC (2007) New risk or old risk, high risk or no risk? How scientists' standpoints shape their nanotechnology risk frames. Health Risk Soc 9(2):173-190. https://doi. org/10.1080/13698570701306872

Priest SH (2011) Nanotechnology and the public: risk perception and risk communication. CRC Press Taylor \& Francis Group, Boca Raton

Priest S, Lane T, Greenhalgh T, Hand LJ, Kramer V (2011) Envisioning emerging nanotechnologies: a three-year panel study of South Carolina citizens. Risk Anal 31(11):1718 1733. https://doi.org/10.1111/j.1539-6924.2011.01705.x

Renn O, Roco MC (2006) Nanotechnology and the need for risk governance. J Nanopart Res 8(2):153-191. https://doi. org/10.1007/s11051-006-9092-7

Satterfield T, Kandlikar M, Beaudrie CE, Conti J, Harthorn BH (2009) Anticipating the perceived risk of nanotechnologies. Nat Nanotechnol 4(11):752-759

Scheufele DA, Lewenstein BV (2005) The public and nanotechnology: how citizens make sense of emerging technologies. J Nanopart Res 7(6):659-667. https://doi.org/10.1007/s11051005-7526-2

Scheufele DA, Corley EA, Dunwoody S, Shih TJ, Hillback E, Guston DH (2007) Scientists worry about some risks more than the public. Nat Nanotechnol 2(12):732-734. https://doi. org/10.1038/nnano.2007.392

Scheufele DA, Corley EA, Shih TJ, Dalrymple KE, Ho SS (2009) Religious beliefs and public attitudes toward nanotechnology in Europe and the United States. Nat Nanotechnol 4(2):9194. https://doi.org/10.1038/nnano.2008.361

Shatkin JA, Abbott LC, Bradley AE, Canady RA, Guidotti T, Kulinowski KM, Löfstedt RE, Louis G, MacDonell M, 
Maynard AD, Paoli G, Sheremeta L, Walker N, White R, Williams R (2010) Nano risk analysis: advancing the science for nanomaterials risk management. Risk Anal 30(11):16801687. https://doi.org/10.1111/j.1539-6924.2010.01493.x

Siegrist M, Cousin ME, Kastenholz H, Wiek A (2007) Public acceptance of nanotechnology foods and food packaging: the influence of affect and trust. Appetite 49(2):459-466. https://doi.org/10.1016/j.appet.2007.03.002

Silva CL, Jenkins-Smith HC (2007) The precautionary principle in context: US and EU scientists' prescriptions for policy in the face of uncertainty. Soc Sci Q 88(3):640-664. https://doi. org/10.1111/j.1540-6237.2007.00476.x

Slovic P (2000) The perception of risk. Earthscan Publications, London

Su LYF, Cacciatore MA, Brossard D, Corley EA, Scheufele DA, Xenos MA (2015) Attitudinal gaps: how experts and lay audiences form policy attitudes toward controversial science. Sci Public Policy 43(2):196-206. https://doi.org/10.1093 /scipol/scv031

Tachikawa M (2012) Uncertainty of, and stakeholder response to, emerging technologies: food nanotechnology in Japan. ESEP 12(2):113-122. https://doi.org/10.3354/esep00127 van Dijk H, Fischer AR, Marvin HJ, van Trijp HC (2017) Determinants of stakeholders' attitudes towards a new technology: nanotechnology applications for food, water, energy and medicine. J Risk Res 20(2):277-298. https://doi. org/10.1080/13669877.2015.1057198

Vandermoere F, Blanchemanche S, Bieberstein A, Marette S, Roosen J (2010) The morality of attitudes toward nanotechnology: about god, techno-scientific progress, and interfering with nature. J Nanopart Res 12(2):373-381. https://doi. org/10.1007/s11051-009-9809-5

Wang J, Gerlach JD, Savage N, Cobb GP (2013) Necessity and approach to integrated nanomaterial legislation and governance. Sci Total Environ 442:56-62. https://doi.org/10.1016 /j.scitotenv.2012.09.073

Publisher's note Springer Nature remains neutral with regard to jurisdictional claims in published maps and institutional affiliations. 